\title{
Concurrent Speech Planning Does Not Eliminate Repetition Priming From Spoken Words: Evidence From Linguistic Dual-Tasking
}

\author{
Federica Bartolozzi and Suzanne R. Jongman \\ Max Planck Institute for Psycholinguistics, Nijmegen, \\ the Netherlands
}

\author{
Antje S. Meyer \\ Max Planck Institute for Psycholinguistics, Nijmegen, the \\ Netherlands, and Radboud University
}

\begin{abstract}
In conversation, production and comprehension processes may overlap, causing interference. In 3 experiments, we investigated whether repetition priming can work as a supporting device, reducing costs associated with linguistic dual-tasking. Experiment 1 established the rate of decay of repetition priming from spoken words to picture naming for primes embedded in sentences. Experiments 2 and 3 investigated whether the rate of decay was faster when participants comprehended the prime while planning to name unrelated pictures. In all experiments, the primed picture followed the sentences featuring the prime on the same trial, or 10 or 50 trials later. The results of the 3 experiments were strikingly similar: robust repetition priming was observed when the primed picture followed the prime sentence. Thus, repetition priming was observed even when the primes were processed while the participants prepared an unrelated spoken utterance. Priming might, therefore, support utterance planning in conversation, where speakers routinely listen while planning their utterances.
\end{abstract}

Keywords: repetition priming, speech comprehension, speech planning, divided attention

Supplemental materials: http://dx.doi.org/10.1037/xlm0000944.supp

Holding a conversation seems an effortless task, yet it requires tight coordination between the speakers. Indeed, analyses of corpora of conversational speech suggest that gaps between turns are often only around 200 to $300 \mathrm{~ms}$ in duration (Levinson \& Torreira, 2015). By contrast, laboratory studies of word production, usually for picture naming, report latencies of at least $600 \mathrm{~ms}$ (Indefrey \& Levelt, 2004), and sentence production latencies often exceed a second (Allum \& Wheeldon, 2007; Smith \& Wheeldon, 1999). Some studies have suggested that short gaps in conversation arise because next-turn speakers start planning a response before the end of their interlocutor's turn (Levinson \& Torreira, 2015). This means that speech planning and comprehension might overlap in time, a process that we will refer to as linguistic dual-tasking. Early planning may support fast turn-taking, but it should impose a substantial cognitive load because comprehension and speech planning processes must be performed simultaneously. It is unclear how interlocutors deal with these processing costs. In this study we explore whether the burden of linguistic dual-tasking can be re-

This article was published Online First October 8, 2020.

(D) Federica Bartolozzi and Suzanne R. Jongman, Max Planck Institute for Psycholinguistics, Nijmegen, the Netherlands; Antje S. Meyer, Max Planck Institute for Psycholinguistics, and Donders Institute for Brain, Cognition and Behaviour, Radboud University.

Suzanne R. Jongman is now at the Department of Psychology, University of Illinois, Urbana-Champaign.

Correspondence concerning this article should be addressed to Federica Bartolozzi, Max Planck Institute for Psycholinguistics, PO Box 310, 6500 AH Nijmegen, the Netherlands. E-mail: federica.bartolozzi@mpi.nl duced by repetition priming, which has already been identified as a pivotal mechanism in models of conversation (Pickering \& Garrod, 2004, 2013).

\section{Linguistic Dual-Tasking in Conversation}

Previous experimental work has shown that speakers often start planning responses while still listening to their interlocutors (Barthel, Meyer, \& Levinson, 2017; Barthel, Sauppe, Levinson, \& Meyer, 2016; Bögels, Casillas, \& Levinson, 2018; Bögels, Magyari, \& Levinson, 2015; Corps, Crossley, Gambi, \& Pickering, 2018; Lindsay, Gambi, \& Rabagliati, 2019; Magyari, De Ruiter, \& Levinson, 2017). These studies have also revealed that such linguistic dual-tasking reduces turn gaps, but that speech planning is less efficient than when it occurs in silence (Fairs, Bögels, \& Meyer, 2018; Fargier \& Laganaro, 2016, 2019). For instance, in a study by Bögels et al. (2015) participants answered quiz-style questions, such as "Which character, also called $\mathbf{0 0 7}$, appears in the famous movies?". There were two experimental conditions. In the early cue condition, the cue to the answer (007 in the example) appeared in the middle of the question, whereas in the late cue condition, it occurred at the very end, as in "Which character from the famous movies, is also called 007?". The participants were asked to answer as fast as possible. Speech onset latencies measured from the end of the question were shorter in the early cue $(640 \mathrm{~ms})$ than in the late cue condition $(950 \mathrm{~ms})$, indicating that in the early cue condition participants started planning their response during the question. Yet, the response time advantage $(310 \mathrm{~ms}$ ) was much less than the time between the cues in the two conditions $(1,707 \mathrm{~ms})$. This means that participants' response planning was less efficient in the early cue than in the late cue condition. If 
planning had been equally efficient in both conditions, responses in the early cue condition should have started well before, rather than after the end of the question.

The results of the study by Bögels et al. (2015) are consistent with numerous word production studies that have shown, first, that speech planning requires attention and, therefore, suffers when carried out concurrently with another task that also requires attention (e.g., Almor, 2008; Boiteau, Malone, Peters, \& Almor, 2014; Sjerps \& Meyer, 2015) and, second, that interference arises when linguistic representations are activated simultaneously for speech comprehension and production. For instance, in dual-task experiments, there is more mutual interference when picture naming is combined with syllable than with tone monitoring (Fairs et al., 2018; Fargier \& Laganaro, 2016). This indicates that the spoken distractors are processed and affect speech planning.

The experimental work on linguistic dual-tasking suggests that speaking in conversation should be rather effortful. However, these experiments generally employed unrelated production and comprehension stimuli, whereas turns in conversation often have some degree of coherence and refer to the same topic. This means that interlocutors can refer to concepts introduced earlier and use words that have occurred before to refer to relevant entities or events. Thus, they might reduce the linguistic dual-tasking costs by priming each other. The question addressed in the present paper was whether such priming could occur when participants engaged in linguistic dual-tasking, as they often do in natural conversation.

\section{Two Roles of Priming in Conversation}

Priming might aid conversation in two related ways: by affecting the choice of words and, thereby, supporting the creation of common ground between the speakers, and by increasing the speed of comprehension and production processes. Common ground is background knowledge that is shared by the interlocutors and is used to shape and guide conversations (e.g., Clark \& Marshall, 1981). Establishing common ground entails, among other things, that speakers agree on names for referents in common ground (e.g., consistently talking about "the shoe" or "the trainer"). Such agreement renders utterances progressively less ambiguous by establishing single referents for words that could refer to multiple referents; therefore, making them easier to understand. It may also facilitate speech planning by supporting the appropriate choice among alternative ways of referring to referents.

There is a large body of work concerning the processes underlying the establishment of common ground (Arnold, 2016; BrownSchmidt, 2012; Brown-Schmidt \& Duff, 2016; Clark \& Marshall, 1978; Duff, Hengst, Tranel, \& Cohen, 2006; Horton, 2007; Horton \& Gerrig, 2005, 2016). The influential model of dialogue proposed by Pickering and Garrod (2004; Garrod \& Pickering, 2009) highlights the role of priming for the alignment of the interlocutors' situation models, that is, their representations of the situation under consideration. The proposal is that the establishment of shared situation models (called "implicit common ground" by Garrod and Pickering) is strongly driven by "a priming mechanism, whereby encountering an utterance that activates a particular representation makes it more likely that the person will subsequently produce an utterance that uses that representation" (Pickering \& Garrod, 2004, p. 173). This model posits that priming is an automatic and unconscious process, which cascades through the levels of the language system. In other words, priming can arise at one level (e.g., the lexical level) and spread to other levels (e.g., the syntactic and phonological levels), so that interlocutors become fully aligned. Other authors have argued that automatic priming does not suffice to explain the establishment of common ground (e.g., Brown-Schmidt \& Duff, 2016), but that other, more deliberate processes are also involved. Nonetheless, automatic repetition priming is generally seen as one of the mechanisms supporting the establishment of common ground by increasing the likelihood that interlocutors converge on a joint vocabulary to refer to the concepts under consideration.

Priming can affect both the lexical choice and the speed of speech planning, therefore contributing to swift turn-taking. It appears that this potential function of priming in conversation has not been discussed much in the literature but it is central to the current research. In the following section we review studies of repetition priming, which do not directly concern conversational turn-taking but provide information about the conditions under which priming may be expected to occur.

\section{Repetition Priming of Word Production}

There is a large literature showing that recent exposure to a word can facilitate later comprehension or production of the same word (Francis, 2014; McKone, 1995; McKone \& Dennis, 2000; Monsell, Matthews, \& Miller, 1992; Wheeldon \& Monsell, 1992). Many studies of repetition priming have assessed the effects of written or spoken word primes on the subsequent processing of other written or spoken words (e.g., Forster \& Davis, 1984; Versace \& Nevers, 2003), but in the present context studies of primed word production are more relevant. In these studies, participants typically name target pictures. A variety of priming tasks have been used including picture naming, definition naming, and translation (e.g., Barry, Hirsh, Johnston, \& Williams, 2001; Brown, Neblett, Jones, \& Mitchell, 1991; Durso \& Johnson, 1979; Francis, 2014; Heath et al., 2012; Johnson, Paivio, \& Clark, 1996; Mitchell \& Brown, 1988). These studies have shown that repetition can facilitate both object recognition and the retrieval of object names from the mental lexicon. Different proposals have been made about the way repetition might facilitate lexical access; most commonly it is assumed that the repetition benefit arises at the semantic-phonological interface (Monsell et al., 1992; Wheeldon \& Monsell, 1992). As repetition priming effects on picture naming can be observed across long lags between primes and targets, it is often seen as a form of implicit learning, involving long-lasting changes of the activation levels of processing units or their connections (Hughes \& Schnur, 2017; Monsell et al., 1992; Oppenheim, Dell, \& Schwartz, 2010).

Most studies of repetition priming in picture naming used tasks where the participants produced prime words as well as targets. However, since the linguistic representations involved in speaking and listening are largely shared or tightly linked (e.g., McQueen \& Meyer, 2018, for discussion), repetition should also be observed when participants hear prime words and produce picture names. Work from different lines of research supports this prediction.

First, picture-word interference studies, where participants name pictures while listening to distractor words, have sometimes included an identity condition, where the distractor corresponded to the picture name (e.g., Glaser \& Düngelhoff, 1984; Schriefers, 
Meyer, \& Levelt, 1990; see Costa, Miozzo, \& Caramazza, 1999, for a bilingual study). Compared with unrelated and neutral conditions (featuring nonwords or noise as distractors) identity primes yield facilitation, pointing to a repetition benefit.

A second relevant line of work is research on the lexical boost in structural priming. Structural priming is the observation that speakers become more likely and sometimes faster to use certain grammatical structures (e.g., passives) after exposure to these structures (e.g., Bock, 1986; Bock, Dell, Chang, \& Onishi, 2007; Dell \& Ferreira, 2016). Structural priming effects can be boosted when prime and target sentences share content words (e.g., Cleland \& Pickering, 2003; Segaert, Kempen, Petersson, \& Hagoort, 2013; Segaert, Wheeldon, \& Hagoort, 2016). This indicates repetition priming from words embedded in the priming sentences. The lexical boost effect has been found to be more short-lived than the structural priming effect and has, therefore, been proposed to be an episodic memory effect (Hartsuiker, Bernolet, Schoonbaert, Speybroeck, \& Vanderelst, 2008).

Third, there is a substantial body of work that is related to the work on common ground mentioned earlier and concerns the way utterances are produced when they refer to novel concepts versus concepts introduced earlier. The key observation is that utterances that refer to concepts mentioned earlier are reduced in duration, specifically those words that have occurred before (e.g., Bard, Aylett, Trueswell, \& Tanenhaus, 2004; Jacobs, Yiu, Watson, \& Dell, 2015; Kahn \& Arnold, 2015). A widely discussed issue is whether reductions serve audience design, that is, occur for the benefit of the listener, or result from speaker-internal processes. Most important for the present discussion is the observation that repeated words are sometimes not only reduced in duration but also initiated earlier. For instance, Kahn and Arnold (2015; Experiment 2B) had two participants (a speaker and a listener) perform a joint task. One of them saw an event on their screen and had to instruct the other participant to create the same event on their screen using utterances such as Make the [object] flash. The speaker would then instruct the listener to move another object (identical or different than the previous one). The speaker initiated this utterance faster and reduced their duration when the object name was repeated rather than novel, regardless of whether they or their partner had just produced the object name. These findings indicate repetition priming, that is, facilitation of speaker-internal processes from heard words onto speech production.

In summary, there is strong evidence that word production may be speeded by repetition priming from words heard earlier. In the following sections we consider three factors that may limit the strength of such repetition priming effects in conversation: the lag between primes and targets, the embedding of primes in sentence contexts, and linguistic dual-tasking. The latter factor was assessed in an earlier study in our lab (Jongman \& Meyer, 2017), which will be described below, as well as in the present study.

\section{Limiting Conditions for Repetition Priming}

Turning first to the lag between primes and targets, many studies have highlighted the longevity of repetition priming effects. For instance, repetition benefits for picture naming have been reported after several days or even years (Cave, 1997; Mitchell, 2006; van Turennout, Bielamowicz, \& Martin, 2003). Other studies have varied the lag between prime and target within experimental ses- sions (e.g., Durso \& Johnson, 1979; Wheeldon \& Monsell, 1992). Repetition priming effects tend to decay over time and/or with the amount of intervening materials, but are nonetheless still measurable after considerable delays. Durso and Johnson (1979) reported a repetition priming effect for lags up to 50 intervening items. Wheeldon and Monsell (1992) reported a repetition priming effect for lags ranging between two and seven items (10-35 s, short lag condition) and a weaker effect for lags ranging between 60 and 120 items (6-12 min, long lag condition). However, in all of the picture naming studies, participants produced the primes, either in response to definitions or to pictures. Thus, there appears to be no evidence of the longevity of repetition priming from heard words to picture names. Given that repetition priming effects are generally weaker from heard than produced primes, it is not obvious that priming effects from heard primes will be maintained over longer lags. Consistent with this suggestion, the lexical boost effect described above has been characterized as short-lived.

Next we consider the effect of embedding primes in sentence contexts. Sentential embedding of primes has often been studied in paradigms involving target comprehension (Coane \& Balota, 2010; Levy \& Kirsner, 1989; MacLeod, 1989; Masson \& Macleod, 2000; Oliphant, 1983; Speelman, Simpson, \& Kirsner, 2002). A robust finding is that sentential embedding reduces and sometimes eliminates repetition priming effects. A word production study using embedded primes was conducted by Francis, Camacho, and Lara (2014). In the priming phase of this study, bilingual participants translated words presented either in sentence context or in isolation. In the test phase, they were asked to translate words or to name pictures. As in the comprehension studies, the priming effect was reduced when words were initially translated in context rather than in isolation. An account of the effects of contextual embedding on repetition priming is that embedding prime words in sentences or, in fact, lists of words, affects the way these items are encoded (Masson \& MacLeod, 2000). According to this view, the distinctiveness account, priming effects are strongest when the primes are "distinctively encoded and individuated against the background of other items that are presented" (p. 1096).

None of the studies on the effects of presenting primes in context has involved the task combination at issue here, namely listening to primes and producing target words. However, the distinctiveness account, if valid, should apply here as well. Consequently, one would expect weaker repetition priming from contextually embedded spoken prime words onto word production than from isolated prime words. Recall though that priming effects from heard primes embedded in sentences were found in the research on the syntactic boost effect and on audience design described above.

Finally, we consider whether repetition priming can occur when speakers are planning utterances while hearing the primes. This is important because, as indicated above, speakers often engage in planning while listening to their interlocutor, dividing attention between comprehension and production processes. Many studies of verbal memory have assessed the effects of divided compared with full attention to word processing on later memory. As one might expect, the effects depend on many variables, including the type and difficulty of the secondary task and the way memory is assessed, in particular through explicit memory (recall or recognition of words) or implicit memory tasks (most commonly word fragment completion, word association, category-exemplar gener- 
ation; e.g., Gabrieli et al., 1999; Mulligan \& Stone, 1999; Wolters \& Prinsen, 1997; for a review see Spataro, Cestari, \& RossiArnaud, 2011). The emerging pattern is that divided attention can reduce priming effects when the secondary task is difficult (Mulligan, 1997, 1998). Furthermore, the results suggest that at least some attention to the prime is needed for priming effects to occur (e.g., Keane, Cruz, \& Verfaellie, 2015; MacDonald \& MacLeod, 1998; Mulligan, 1998).

Repetition during linguistic dual-tasking has so far only been investigated by Jongman and Meyer (2017). On each trial of this study participants heard a prime word and simultaneously saw a distractor picture followed by a target picture. The prime was identical to the name of the target, associatively related to it, or unrelated. In the no-plan condition, participants were asked to name only the target picture; in the plan condition, they had to name both the distractor and the target picture. Condition was manipulated between participants in Experiment 1 and within participants in Experiment 2. While associative priming was absent in the plan condition of Experiment 2, robust repetition priming was found in the plan and no-plan conditions of both experiments. Thus, there was repetition priming from hearing prime words to producing them as picture names, even during dual-tasking.

In summary, the existing literature shows that repetition priming can arise when prime and target are separated by intervening items, when the primes appear in utterance contexts, and when participants engage in other tasks, including speech planning, while processing the primes. However, no study has investigated whether repetition priming occurs when these conditions are met simultaneously, as will often be the case in conversation. That is, it is not known whether repetition priming from comprehending a prime word to producing that word occurs when the prime is embedded in an utterance context, when there is a lag between prime and target, and when the participant is preparing an utterance while hearing the prime. The goal of the present study was to answer this question. The results should contribute to a better understanding of the cognitive processes underlying repetition priming. More importantly, they should provide new evidence about the potential importance of repetition priming for alignment and swift turn-taking in conversation.

\section{The Current Study}

The paradigm used in the present study was similar to the paradigm used by Jongman and Meyer (2017). The participants heard prime words and produced target words as picture names. However, in contrast to the earlier study, the primes were embedded in sentence contexts. On the trials of Experiment 1, participants listened to a sentence containing a prime word (e.g., Hij heeft helaas de radio kapotgemaakt, Unfortunately he has broken the radio) and saw two pictures one after the other, Picture 1 and Picture 2, which they had to name (see Figure 1). The prime word could be identical or unrelated to Picture 2 (the target), and was always unrelated to Picture 1. Picture 1 appeared after the offset of the sentence (i.e., in silence), $2 \mathrm{~s}$ after sentence onset. The prime sentence and Picture 2 appeared on the same trial (no lag condition), or were separated by 10 or 50 intervening trials (short lag and long lag condition, respectively). Pictures 2 in the short lag
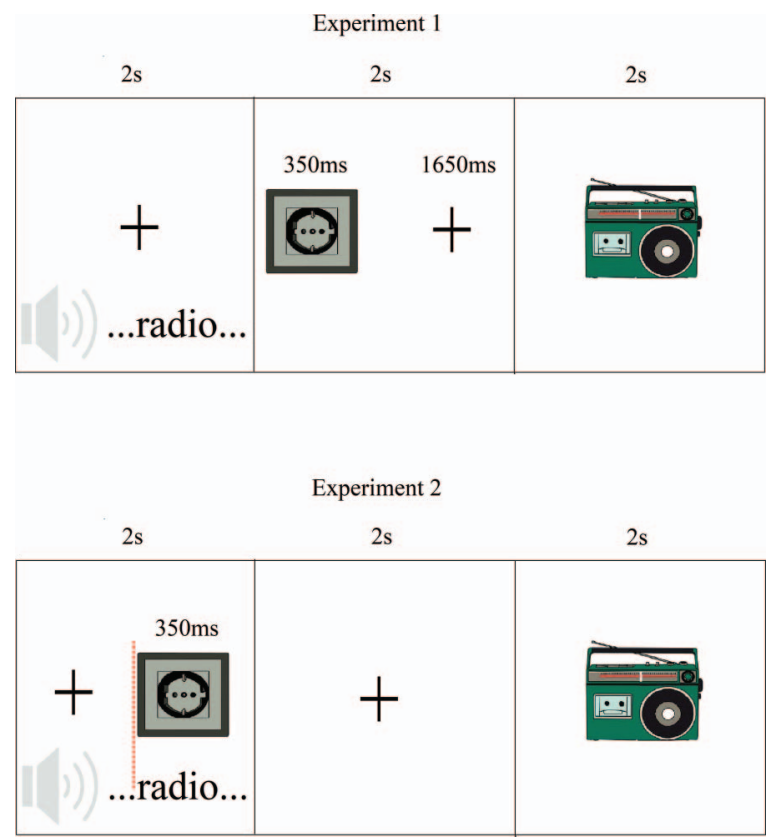

Figure 1. Trial structure in Experiments 1 and 2. This example shows a trial in the no lag condition. In each trial, participants hear a prime word (e.g., radio), and see two pictures, Picture 1 (e.g., socket) and Picture 2 (e.g., radio). See the online article for the color version of this figure.

condition occurred $1 \mathrm{~min}$ after the prime, Pictures 2 in the long lag condition occurred 5 min after the prime.

This experiment studied whether repetition priming from word comprehension to picture naming occurs when the primes are embedded in a sentence context, and explored how any priming effects would change when prime and target follow each other immediately or are separated in time and by intervening materials. As reviewed above, the relevant literature does not reveal how the effects of contextual embedding and lag might combine for the types of prime and target stimuli at issue here. Our prediction was that the priming effect should be strong (possibly equivalent to the effect obtained by Jongman and Meyer (2017) for word primes) in the immediate condition, but should decrease across lags.

Experiment 2 used the same paradigm to determine whether priming was affected by division of attention between comprehension and concurrent speech-planning. Unlike Experiment 1, Picture 1 now appeared at the onset of the prime word in the sentence. Therefore, participants initiated speech planning while still comprehending the sentence. In the study by Jongman and Meyer (2017), the repetition priming effect was unaffected by division of attention. Here we studied whether this was also the case when the primes were embedded in sentence contexts and when prime and target were separated in time. If the amount of attentional resources allocated to the comprehension task in Experiment 2 allows enough processing of the stimulus, the magnitude and the rate of decay of the priming effect should be similar in Experiments 1 and 2. By contrast, if splitting attention between the comprehension and production task does not enable thorough processing of the auditory stimulus, the rate of decay of the priming effect should be greater in Experiment 2 than in Experiment 1 . 
Any priming effects obtained in Experiment 2 might be influenced by task demands. Given that the relationship between prime and Picture 2 in the no lag condition was quite obvious, participants might strategically pay attention to the auditory input because it may support subsequent picture naming. For this reason, we also carried out a modified version of Experiment 2 in which the no lag condition was removed (Experiment 3).

In the study by Jongman and Meyer, prime words and target pictures were repeated 12 times during the experiment (six times as prime and six times as target). Some studies have shown that prime and/or target repetition may increase the size of priming effects (Jacoby \& Dallas, 1981). In the present study, primes and targets were only presented once, thereby allowing us to assess whether repetition priming would be obtained when the experimental items were not repeated.

\section{Experiment 1}

In the first experiment, participants heard sentences containing a prime word and were subsequently asked to name first Picture 1 and then Picture 2. The name of Picture 2 was either identical or unrelated to the prime word. In the no lag condition Pictures 2 appeared on the same trial as the prime word, in the short lag condition they appeared 10 trials $(1 \mathrm{~min})$ after the prime word, and in the long lag condition, they appeared 50 trials $(5 \mathrm{~min}$ ) after the prime word. We refer to the conditions as no, short or long lag conditions, but it is important to point out that time and number of intervening items may differentially contribute to the rate of decay of the priming effect (McKone, 1998). Picture 1 was presented after the prime sentence had ended, ensuring no overlap between the presentation of the prime and Picture 1. The main aim of Experiment 1 was to replicate previous studies that found decay of the priming effect as a function of time/number of intervening trials, with the novel addition of embedding the prime in a sentence context. This configuration was intended to mimic situations occurring in conversation where a word in one speaker's turn might prime the next speaker's use of the same word.

\section{Method}

Power analysis. To determine whether we would be able to detect an effect of Condition on Picture 2 latencies, we carried out a power analysis. Condition was modeled using Helmert contrasts, as in the main experiments. The first contrast compared the unrelated condition against all the other conditions, the second contrast compared the long lag condition against the short lag and no lag conditions, and the third contrast compared the short lag condition against the no lag condition. In the simulation $(n=1,000)$, the significance of each contrast was tested by comparing the model that included all contrasts with the model that did not include the contrast of interest. The mean response times (RTs) for each condition for the power analysis were taken from Experiment 1 in Jongman and Meyer (2017), which offers the best approximation to our conditions and design. In their experiment, the mean naming latency in the identical priming condition was $597 \mathrm{~ms}$ and mean naming latency in the unrelated condition was $679 \mathrm{~ms}$. The estimates for the short and long lag condition were chosen on the basis of the results obtained by Wheeldon and Monsell (1992), who tested word-to-picture priming at longer delays. In their experi- ment, the mean naming latency in the long lag condition (prime and target separated by 60-120 lags, 6-12 min) increased by $4.73 \%$ with respect to the short lag condition (prime and target separated by 2-7 lags, 10-35 ms). The estimates in Wheeldon and Monsell (1992) for the short lag and unrelated condition, 592 and $688 \mathrm{~ms}$, respectively, were similar to those obtained for the immediate and unrelated condition in Jongman and Meyer (2017). Therefore, we first calculated the percentage of mean latency increase from the short lag to the long lag condition in Wheeldon and Monsell (1992). We then applied this percentage increase to Jongman and Meyer's identical condition, so as to build a mean naming latency for our short and long lag conditions. As a result, in our power analysis we used a mean naming latency of $625 \mathrm{~ms}$ for both the short and long lag conditions.

Assuming 160 items and 40 participants, the simulated data yielded a power of 0.91 at $\alpha=.05$. The power analysis and the raw data of each of the experiments presented in this paper are available on the MPI for Psycholinguistics Archive (https://archive.mpi .nl/mpi/).

Participants. Forty participants ( 8 male, $M_{\text {age }}=22.65$ years, range $=18-27$ years) took part in Experiment 1 . They were recruited from the Max Planck Participant Database, were native speakers of Dutch, did not report any speech problems, and had normal or corrected-to-normal vision. Participants received $8 €$ as compensation for taking part in the study. Ethical approval for all experiments reported here was granted by the Social Sciences Faculty of Radboud University.

Design. The experiment included 290 trials. During each trial, participants listened to a sentence containing a prime word (e.g., Hij heeft helaas de radio kapotgemaakt, Unfortunately he has broken the radio) and then saw two pictures, Picture 1 and Picture 2, which they had to name (see Figure 1). In Experiment 1, Picture 1 was presented at the end of the sentence, allowing participants to process the prime in silence. Picture 2 was presented $2 \mathrm{~s}$ after the onset of Picture 1.

Out of the 290 trials, 130 trials were filler trials. Fifty of the filler trials were presented at the beginning of the experiment to allow for an even spread of long lag trials across the experiment, rather than presenting them all towards the end. These filler items did not include prime words. In the remaining 80 filler trials, the sentence contained a prime word that corresponded to a Picture 2 name on a different trial (i.e., the prime sentence in the lag conditions, see below). Responses to pictures on filler trials were not analyzed.

Additionally, 160 trials were experimental trials. Picture 1 was always unrelated to the prime word in the trial. Picture 2 was always a target picture and, as described above, appeared in one of four different conditions: the no lag condition, short lag condition, long lag condition, and unrelated condition. In the no lag condition, Picture 2 was immediately preceded by a sentence containing its name. For example, the picture of a radio appeared on the same trial as the sentence Hij heeft helaas de radio kapotgemaakt. In the short lag condition, Picture 2 appeared 10 trials (corresponding to $1 \mathrm{~min}$ ) after the sentence containing the prime; in the long lag condition, Picture 2 appeared 50 trials (corresponding to $5 \mathrm{~min}$ ) after the sentence containing its prime; in the unrelated condition, the label of Picture 2 did not occur anywhere else in the experiment. 
We created four item lists. Each list included all experimental and filler items. Condition was counterbalanced across items. That is, in each list, 40 different Picture 2's appeared in each condition. Each list was presented to 10 participants. Participants were randomly assigned to lists.

\section{Materials.}

Sentences. A female speaker of Dutch produced the sentences with neutral intonation. Recordings were made in a soundproof booth using a Sennheiser ME 64 microphone. Sentences were recorded using the software Audacity (Team, A, 2012). All sentences had a length below 2,000 ms (average length $=1,879 \mathrm{~ms}$, range $=1,493-2,000 \mathrm{~ms}$ ). Two sentences that were initially longer than 2,000 ms (2,054 and 2,060 ms) were compressed using Praat (Version 5.1; Boersma \& Weenink, 2005). The auditory stimuli were normalized to ensure that they had similar intensity. Each sentence included one concrete noun, the prime. The prime was preceded by an adverb and followed by a past participle (e.g., Hij heeft helaas de radio kapotgemaakt, "He has unfortunately the radio broken").

Pictures. There were 307 pictures, all taken from the MultiPic database (Duñabeitia et al., 2017). Of these, 145 pictures were chosen as Picture 1 and 160 pictures were chosen as Picture 2. Two pictures appeared on practice trials. Repetition of some pictures was necessary because the database did not include enough suitable pictures. Items chosen as Picture 1 had a mean name agreement of $87.65 \%$ (range $=38.60-100 \%$ ) and mean frequency (fpm, frequency per million in the SUBTLEX database; Keuleers, Brysbaert, \& New, 2010) of 112.87 (range $=0.02-4412.02$ ). Some of the items chosen as Picture 1 were repeated across the experiment as Picture 1 in other experimental trials (15 items, repeated twice) or as Picture 1 or Picture 2 in filler trials. These items were repeated for a maximum of three times throughout the experiment. Items chosen as Picture 2 had a mean name agreement of $92.82 \%$ (range $=54.39-100 \%)$ and a mean frequency of 8.83 (range $=$ 0.02-29.29). All Picture 2 names were low to medium in frequency (fpm $<30$; words with fpm $<5$ are traditionally classified as low-frequency words, words with fpm $>100$ are traditionally classified as high-frequency words; Brysbaert, Mandera, \& Keuleers, 2018). Low- to medium-frequency items were preferred over high-frequency ones because priming effects are usually larger for low- than for high-frequency targets (Wheeldon \& Monsell, 1992). Picture 2 items were never repeated.

Procedure. All trials had the same structure (see Figure 1). At trial onset participants heard a sentence containing a prime word while looking at a fixation cross. Sentence duration was maximally $2 \mathrm{~s}$. Two seconds after the onset of the sentence, the fixation cross was substituted by Picture 1, which was shown for $350 \mathrm{~ms}$ and followed again by a fixation cross. Two seconds after the onset of Picture 1, the fixation cross was replaced by Picture 2. Picture 2 remained on screen for $2 \mathrm{~s}$, the second response window. The SOA between the onset of the sentence and the onset of Picture 2 was $4 \mathrm{~s}$. At the offset of Picture 2, a new trial began. Each trial lasted $6 \mathrm{~s}$ in total. Participants were instructed to listen to the sentences and name each picture as soon as it appeared on the screen. The experiment lasted about $40 \mathrm{~min}$.

Before the beginning of the experiment, participants carried out a practice session to familiarize them with the task. The practice session included four trials, which were structured as the trials in the actual experiment. We presented two trials in the no lag condition, and two trials in the unrelated condition.

Apparatus. The experiment was controlled using the software Presentation (Version 20.0, www.neurobs.com). Sentences were played using headphones (Sennheiser HD 437) and responses were recorded using a Sennheiser ME 64 microphone. Stimuli were presented on a 17" monitor (Iiyama LM 704U7).

Scoring and analysis. Responses to the pictures were coded as correct if participants used the dominant name in the picture database, which, for Picture 2 items, corresponded to the primes. A trial was coded as correct when both Picture 1 and Picture 2 were named correctly, and as incorrect if one of the two pictures or both were named incorrectly. Only correct trials were included in the analyses of response latencies.

Three items, used as Picture 1 in experimental trials or as Picture 1 and 2 in filler trials, were mistakenly presented four times (instead of three times) in some of the lists. Therefore, we removed the experimental trials where these items occurred for the fourth time. One experimental item was removed from all lists because it was erroneously repeated. Response latencies were measured manually by the first author using the software Praat (Version 5.1; Boersma \& Weenink, 2005).

Data from experimental trials were analyzed using mixed effects models (package lme4, Version 1.1.14; Bates, Mächler, Bolker, \& Walker, 2015) in R (Team R. C., 2017, Version 3.4.1). We modeled the rates of accurate responses to Picture 1 and Picture 2 and the naming latencies for both pictures on correct trials (i.e., trials where both pictures were named correctly).

The most important dependent variable was the naming latency for Picture 2. Because the naming latencies were right-skewed, they were log-transformed and then trimmed by participant and condition using a cut-off value of $2.5 S D$ beyond the mean (values outside the cut-off were excluded). Picture 1 latencies were also analyzed to make sure that any differences in Picture 2 latencies (and accuracy) were not related to differences in the difficulty of processing Picture 1. All latencies were analyzed using linear mixed effects models.

Given that in Jongman and Meyer (2017) the rates of correct responses were high and not affected by the primes, we did not predict any priming effects for the rates of correct responses in the present article. However, the primes could, of course, also affect accuracy, and to explore this possibility, accuracy rates for Picture 2 were analyzed as well. Picture 1 accuracy rates were also analyzed. As in the case of Picture 1 latencies, Picture 1 accuracy rates should not depend on the experimental conditions. In both Picture 1 and Picture 2 analyses, Accuracy was a categorical variable $(1=$ correct trial, $0=$ incorrect trial $)$ and was analyzed using generalized mixed effects models.

All the models were run using the optimizer BOBYQA (Powell, 2009). Condition was always the independent variable and modeled using Helmert contrasts. The first contrast compared the unrelated condition to the other conditions (long lag, short lag, no lag), the second contrast compared the long lag condition to the short and the no lag condition, and the third contrast compared the short condition to the no lag condition. While Helmert contrasts can give us information on how priming decays across lags, they do not enable us to directly compare whether each of the priming conditions yields repetition benefits with respect to the unrelated condition. In the model, the intercept represents the overall mean. 
All models were initially built using a maximal random-effects structure. Accuracy and latency models for Picture 2 initially included by-participant and by-Picture 2 intercepts and slopes for Condition. Accuracy and latency models for Picture 1 initially included by-participant and by-Picture 1 intercepts and slopes for Condition. The random-effects structure was then simplified following Bates, Kliegl, Vasishth, and Baayen (2015) to avoid overparametrization. The procedure used to simplify the randomeffects structure of each model is described in the online supplemental material, along with the final model outputs.

\section{Results and Discussion}

Table 1 shows the average accuracy rates and naming latencies for Pictures 1 and 2 per condition, along with the standard deviations. Recall that Picture 1 was always unrelated to the prime and that, consequently, the accuracy rates and latencies should not depend on the priming condition. By contrast, for Picture 2, repetition priming was expected for the response latencies and possibly the accuracy rates. These effects, if present, should decrease across lags.

As can be seen in the table, these predictions were borne out: Picture 1 accuracy rates and latencies were similar across priming conditions, whereas Picture 2 accuracy rates and naming latencies showed evidence for priming.

The statistical analyses confirmed these impressions: the model with accuracy rates for Picture 1 naming included Condition as the independent variable, the random structure included only a byparticipant intercept. Condition was not a significant predictor $\left(\chi^{2}(3)=3.74, p=.29\right)$. The model for log-transformed Picture 1 naming latencies included Condition as the independent variable; the random-effects structure included by-Picture 1 and byparticipant intercepts and slopes for Condition. Including Condition as a predictor did not improve model fit $\left(\chi^{2}(3)=2.35, p=\right.$

Table 1

Mean Accuracy and Naming Latencies, With Standard Deviations in Parentheses, for Picture 1 and Picture 2 in Experiment 1, 2, and 3

\begin{tabular}{cccc}
\hline Picture and condition & Experiment 1 & Experiment 2 & Experiment 3 \\
\hline Picture 1 accuracy $(S D)$ & & & \\
Unrelated condition & $82.00(0.38)$ & $81.38(0.38)$ & $79.18(0.41)$ \\
Long lag condition & $81.00(0.38)$ & $79.94(0.39)$ & $79.43(0.40)$ \\
Short lag condition & $81.56(0.38)$ & $81.50(0.38)$ & $80.63(0.39)$ \\
No lag condition & $84.06(0.36)$ & $80.94(0.39)$ & - \\
Picture 1 latency (SD) & & & \\
Unrelated condition & $717(187)$ & $860(263)$ & $854(286)$ \\
Long lag condition & $724(191)$ & $868(251)$ & $878(323)$ \\
Short lag condition & $715(195)$ & $847(242)$ & $850(283)$ \\
No lag condition & $707(177)$ & $870(186)$ & - \\
Picture 2 accuracy $(S D)$ & & & \\
Unrelated condition & $70.25(0.46)$ & $67.44(0.47)$ & $67.48(0.47)$ \\
Long lag condition & $70.88(0.45)$ & $69.75(0.46)$ & $68.11(0.46)$ \\
Short lag condition & $72.88(0.44)$ & $71.44(0.45)$ & $71.26(0.45)$ \\
No lag condition & $81.38(0.39)$ & $77.19(0.42)$ & - \\
Picture 2 latency (SD) & & & \\
Unrelated condition & $769(214)$ & $821(263)$ & $815(238)$ \\
Long lag condition & $758(209)$ & $819(251)$ & $812(235)$ \\
Short lag condition & $744(191)$ & $789(242)$ & $798(239)$ \\
No lag condition & $618(159)$ & $638(186)$ & - \\
\hline
\end{tabular}

.50). Thus, as anticipated, responses to Picture 1 were not systematically affected by Condition.

By contrast, effects of Condition were found for the responses to Picture 2: The model for accuracy rates included Condition as the independent variable; and the random-effects structure included by-Picture 2 and by-participant intercepts. Including Condition improved model fit $\left(\chi^{2}(3)=86.90, p<.002\right)$. All contrasts were significant. In particular, the comparison between the unrelated condition and all other conditions together (first contrast) showed that people were more likely to name pictures incorrectly in the unrelated condition. In turn, items in the long lag condition were more likely to yield incorrect responses than those in the short lag and the no lag conditions together (second contrast). Responses in the short lag condition included more errors than in the no lag condition (third contrast). This means that participants were more likely to name a picture correctly if they had been presented with the prime at any time earlier during the experiment. The priming benefit was, therefore, strongest in the no lag condition and decreased at longer lags.

The model for the log-transformed Picture 2 naming latencies included Condition as the independent variable, and the randomeffects structure included by-participant and by-Picture 2 slopes and intercepts. Condition was a significant predictor $\left(\chi^{2}(3)=\right.$ 76.23, $p<.002)$. Paralleling the results seen for Picture 2 accuracy, response latencies for Picture 2 were shorter when participants had heard the primes earlier in the experiment than when this was not the case. More specifically, the first contrast showed that naming latencies in the unrelated condition were slower than in all other conditions; the second contrast showed that the long lag condition was slower than the short and no lag condition; the third contrast showed that the short lag condition was slower than the no lag condition. As pointed out, the contrasts used in the analysis do not allow us to compare the unrelated condition against each of the priming conditions. However, the mean Picture 2 latencies in the unrelated and long lag conditions were almost identical, suggesting that in the long lag condition repetition benefits might have not occurred. We return to this point in the General Discussion.

The goals of this experiment were to establish that a priming effect would be obtained from the primes embedded in carrier sentences and to determine the stability, or decay, of the effect across lags. The data showed that the effect was the strongest when prime and target were in the same trial and decreased with more intervening items. These results serve as a benchmark for the evaluation of priming effects in Experiments 2 and 3, where primes were presented while the participants prepared utterances.

\section{Experiment 2}

Experiment 1 showed repetition benefits when primes were embedded in sentences. The strongest repetition benefits were obtained in the no lag condition and priming benefits decreased at longer lags. The goal of Experiment 2 was to determine whether the same pattern would hold when the primes were processed during a picture naming task. While the participants of Experiment 1 first listened to the sentence including the prime and then named both Picture 1 and Picture 2, the participants of Experiment 2 saw Picture 1 while listening to the prime word and immediately named it. This forced them to plan a spoken response during the encoding of the prime. Determining whether priming occurred in 
this situation is important because studies of turn-taking suggest that in conversation comprehension and production processes often run in parallel. The division of attention between these processes may affect the way spoken utterances are processed and the impact of spoken primes on word production. If repetition priming did not occur under such circumstances, its value as a tool for supporting fast utterance planning in conversation would be limited. As explained earlier, repetition priming during word planning was also investigated by Jongman and Meyer (2017). However, in their study, primes were repeated 12 times during the experiment (six times as distractor and six times as target), were presented as single words, and immediately preceded the targets. Prime repetition, the (lack of) context and the distance between prime and target have been shown to affect repetition priming effects (e.g., McKone, 1998; Oliphant, 1983; Ostergaard, 1998). Unlike Jongman and Meyer (2017), in the present study the prime words and the targets (our Pictures 2) only occurred once; the primes were presented in carrier sentences, and Pictures 2 occurred in the same trial as the prime, or after a short or longer lag.

\section{Method}

Participants. Forty participants ( 8 male, $M_{\text {age }}=23$, range $=$ 19-28) took part in the study and received $8 €$ as compensation. Inclusion criteria were the same as in Experiment 1. Participants recruited in Experiment 1 were not eligible to take part in Experiment 2.

Apparatus, materials, design and data analysis. The same experimental setup, materials, and design were used as in Experiment 1 . The data analysis was done in the same way as described above.

Procedure. The structure of Experiment 2 was the same as Experiment 1 . The only difference was the timing of the presentation of Picture 1. While in Experiment 1 Picture 1 was presented after the sentence, in Experiment 2 it appeared at the onset of the prime word in the sentence (see Figure 1). Picture 1 stayed on the screen for $350 \mathrm{~ms}$ and was followed by a fixation cross up to the presentation of Picture 2, which remained on screen for $2 \mathrm{~s}$. The gap between the onset of the sentence and the onset of Picture 2 was 4 s, as in Experiment 1.

\section{Results and Discussion}

Average accuracy rates, condition means and standard deviations for Picture 1 and 2 are shown in Table 1 . As can be seen, the results are very similar to those obtained in Experiment 1. Again, the accuracy rates and naming latencies for Picture 1 were largely unaffected by Condition, whereas the accuracy rates and latencies for Picture 2 showed evidence of priming.

We first analyzed Picture 1 accuracy rates. The model included Picture 1 Accuracy as the dependent variable and Condition as the independent variable. The random-effects structure included byparticipant and by-Picture 1 slopes. The model with Condition as predictor did not improve over the null model $\left(\chi^{2}(3)=2.50, p=\right.$ .48). Naming latencies in response to Picture 1 were also unaffected by Condition, as expected $\left(\chi^{2}(3)=3.34, p=.34\right)$. This model included log-transformed naming latencies as the dependent variable and Condition as the independent variable. The randomeffects structure included by-participant and by-Picture 1 slopes and intercepts.
We then turned to the analysis of Picture 2 responses. We first modeled Accuracy rates. Condition was taken as the independent variable; the random-effects structure included a by-Picture 2 slope and by-participant and by-Picture 2 intercepts. Condition improved model fit $\left(\chi^{2}(3)=27.17, p<.002\right)$. All contrasts were significant. Similar results were obtained in the analysis of $\log$ transformed naming latencies in response to Picture 2. Again, Condition was taken as the independent variable; the randomeffects structure included a by-participant slope and by-participant and by-Picture 2 intercepts. Condition improved model fit $\left(\chi^{2}(3)=73.96, p<.002\right)$. As in the analysis of accuracy rates, all contrasts were significant. Again, this means that naming latencies in the unrelated condition were the slowest, that naming latencies in the long lag condition were slower than those in the short lag and no lag condition together, and that naming latencies in the short lag condition were slower than those in the no lag condition. Even if these results cannot give us specific information about the priming condition at which repetition priming can no longer be observed, mean naming latencies in the long lag condition were virtually identical to those in the unrelated condition, suggesting that at this point repetition did not yield any benefits, just as in Experiment 1. Overall though, our results suggest that, even when the cognitive load of the encoding task was increased by having participants perform the comprehension task together with a picture naming task, priming effects still occurred both in terms of higher accuracy rates and decreased latencies.

Finally, we compared the repetition benefits for the Picture 2 latencies in Experiment 1 and Experiment 2. The model included log-transformed naming latencies as the dependent variable, and Condition, Experiment, and their interaction as the independent variables. The random-effects structure included by-participant slopes and intercepts for Condition, and by Picture 2 slopes and intercepts for Condition and Experiment. While both Condition $\left(\chi^{2}(3)=145.02, p<.002\right)$ and Experiment $\left(\chi^{2}(1)=5.78, p=\right.$ $.02)$ improved model fit, their interaction did not $\left(\chi^{2}(3)=3.32\right.$, $p=.35)$. This means that repetition affected naming latencies equally in Experiments 1 and 2, despite the additional load imposed by the planning task in Experiment 2. Indeed, the priming effects for Picture 2 were very similar across experiments. The difference between the unrelated and the no lag condition was 151 $\mathrm{ms}$ in Experiment 1 and $183 \mathrm{~ms}$ in Experiment 2. The difference between the unrelated condition and the short lag condition was 26 $\mathrm{ms}$ in Experiment and $31 \mathrm{~ms}$ in Experiment 2, and as far as the long lag condition is concerned, the difference between the unrelated condition and the long lag condition was $11 \mathrm{~ms}$ in Experiment 1 and $2 \mathrm{~ms}$ in Experiment 2, suggesting that at this point repetition might not be beneficial for picture naming.

While the priming effects did not differ across experiments, the average naming latency for Picture 2 was longer in Experiment 2 than in Experiment 1. Since Picture 2 was always named in silence, without any concurrent task, we had not predicted a main effect of Experiment. The fact that latencies were longer in Experiment 2 than in Experiment 1 suggests that some degree of interference between speech-planning and comprehension still arose in Experiment 2 when Picture 2 was named. We hypothesize that slower Picture 2 naming in Experiment 2 resulted from the additional processing load arising during the parallel (rather than sequential) processing of Picture 1 and the sentence, which then spilled over into Picture 2 naming latencies. Indeed, Picture 1 
mean naming latencies in Experiment 2 were almost $150 \mathrm{~ms}$ slower than in Experiment 1 (716 ms in Experiment 1 and $862 \mathrm{~ms}$ in Experiment 2), indicating that Picture 1 naming was indeed more efficient in silence than during sentence comprehension.

\section{Experiment 3}

Experiments 1 and 2 yielded robust repetition priming effects, regardless of whether the participants heard the prime and then named a picture or heard it while naming a picture. The comparison between the experiments revealed that dividing attention between comprehension and production did not affect the size of priming effects at any of the lags. In these experiments, the relationship between prime and Picture 2 was rather obvious because during no lag trials Picture 2 immediately followed the priming sentence. Participants might have been encouraged to pay attention to the spoken sentences because on these trials processing the prime was beneficial to the subsequent picture naming task. The goal of Experiment 3 was to measure priming effects when the relationship between prime and Picture 2 was less obvious. This was accomplished by removing trials where Picture 2 immediately followed the prime and by only including the short and the long lag condition (lags of 10 and 50 trials).

\section{Method}

Participants. We recruited 40 participants (10 male, $M_{\text {age }}=$ 23.03 years, range $=18-28$ years), who had not taken part in Experiments 1 or 2 . Inclusion criteria and compensation were the same as in Experiments 1 and 2.

Apparatus, materials, and design. Design, apparatus and scoring in Experiment 3 were the same as Experiments 1 and 2.

Procedure. Experiment 3 was identical to Experiment 2, with the only exception that the no lag condition was removed, which resulted in Condition having only three levels (short lag, long lag, and unrelated).

Materials. The no lag condition trials and the 25 filler trials with identical primes and Picture 2 used in Experiments 1 and 2 were turned into unrelated filler trials by substituting the sentences containing the identical prime with new sentences containing unrelated prime words (mean frequency $=21.26$, range $=1.35-$ 128.70 per million in the SUBTLEX database; Keuleers et al., 2010).

\section{Results and Discussion}

Mean accuracy rates, naming latencies and standard deviations for Picture 1 and Picture 2 are reported in Table 1. Condition did not affect either Picture 1 accuracy rates or naming latencies. We first modeled Accuracy with respect to Condition. The randomeffects structure included by-participant and by-Picture 1 intercepts. Condition did not improve model fit $\left(\chi^{2}(2)=1.07, p=.59\right)$. We then ran a model where the dependent variable was logtransformed Picture 1 latency and the independent variable was Condition. Again, the random-effects structure included byparticipant and by-Picture 1 slopes and intercepts. Condition did not improve model fit $\left(\chi^{2}(2)=2.67, p=.26\right)$.

We then turned to the analyses of Picture 2 accuracy rates. The model included Picture 2 accuracy as the dependent variable and
Condition as the independent variable. The random-effects structure included by-participant and by-Picture 2 intercepts. Condition improved model fit $\left(\chi^{2}(2)=9.14, p=.01\right)$. All contrasts were significant.

The same pattern was seen in the analysis of Picture 2 naming latencies. The model included log-transformed Picture 2 naming latencies as the dependent variable and Condition as the independent variable. The random-effects structure included by-participant and by-Picture 2 intercepts. Condition improved model fit $\left(\chi^{2}(2)=13.00, p=.001\right)$; all contrasts were significant, as in the case of Picture 2 accuracy. The first contrast compared the responses in the unrelated condition against the responses in the long and short lag conditions together. Responses were slower in the unrelated condition than in the long and short lag conditions. The second contrast showed that naming latencies in the long lag conditions were slower than those in the short lag condition. We concluded that the priming effects obtained in this study did not depend on the fact that participants strategically paid attention to the prime as a way to improve their performance in the immediately following picture naming task.

\section{General Discussion}

Mutual priming between interlocutors has been argued to contribute considerably to the smooth flow of everyday conversations (Garrod \& Pickering, 2009; Pickering \& Garrod, 2004): using words and structures that the partner has just produced can facilitate speech planning, both by guiding what to say and thereby contributing to building up common ground with the partner and by speeding up utterance planning. There is a large literature reporting robust repetition priming effects under laboratory conditions (e.g., Coane \& Balota, 2010; Francis, Corral, Jones, \& Sáenz, 2008; Monsell et al., 1992; Wheeldon \& Monsell, 1992). However, as these conditions differ in many ways from those prevailing in everyday conversation, we cannot take for granted that repetition priming supports speaking in conversation as effectively as the laboratory studies suggest. We cannot mimic spontaneous conversation in tightly controlled experiments. However, we can experimentally investigate variables that might affect the strength of repetition priming effects and impact its effectiveness in conversation. By doing so, we gain evidence about the mechanisms underlying repetition priming and its importance for conversation.

Following this logic, the current study investigated under which conditions repetition priming occurred from hearing word primes to naming target pictures. A closely related study by Jongman and Meyer (2017) had already established repetition priming from hearing single words to picture naming. Here we extended this work by presenting the prime words in sentence contexts and by varying the lag between prime and target, in terms of time and in terms of the amount of intervening materials. As in the earlier study, we examined whether priming occurred when participants merely listened to the primes and when they prepared to name distractor pictures while hearing the primes.

The results of the three experiments reported above are clearcut: repetition priming facilitated picture naming. The priming effect was seen most strongly in the picture naming latencies but also emerged in the accuracy rates. The effect was moderated by the lag between prime and target, with priming being strongest at 
immediate repetition. Whether or not the participants prepared to name another picture while hearing the prime had little impact on the strength of the priming effect. In the remainder of this discussion, we compare these results to those of earlier studies and discuss the implications for our understanding of repetition priming and its potential role in conversation.

\section{Spoken Words Prime Picture Naming}

As described in the beginning of the article, in most studies of repetition priming in word production participants produced the primes as well as the targets (see Francis, 2014, for a review). Comprehending and producing words involve some shared or closely related representations, but the underlying processes are not identical. If the strength of repetition priming effects depends on the degree of overlap between prime and target representations and processing, heard primes should have weaker effects than self-produced primes onto picture naming. Moreover, merely listening to primes does not require the engagement of attention to the stimuli in the same way as naming primes does, which may also affect the strength of the priming effects. In summary, it is not evident that repetition effects as robust and strong as those seen when participants produce prime words will arise when prime words are merely heard.

The study by Jongman and Meyer (2017) already established that heard primes lead to robust repetition priming for picture naming. The present study replicates this finding. It is consistent with earlier findings by Wheeldon and Monsell (1992), who reported repetition priming for picture naming when the production of the primes was elicited using a definition task (e.g., "Building in which horses are kept" or "An__ a day keeps the doctor away"). It is also consistent with the results obtained by Brown and colleagues (1991), who found comparable priming effects regardless of whether primes were overtly named or not. All of these findings indicate that repetition facilitates lexical access to the picture name (e.g., Barry, Johnston, \& Wood, 2006; Francis et al., 2014; Monsell et al., 1992; Wheeldon \& Monsell, 1992). However, they do not reveal which components of lexical access benefit the most from repetition priming and through which mechanisms the facilitatory effect arises. These issues need to be assessed in further research.

As repetition priming effects are often relatively long-lived, they have been conceptualized as implicit learning processes involving lasting changes of the activation levels of lexical representations and the links between them (e.g., Hughes \& Schnur, 2017; Monsell et al., 1992). As will be further discussed below, the repetition priming effects in the present study were short-lived, compared with those seen in other studies. This may suggest that changes in the representations of words induced by hearing them are shortlived or that part of the repetition priming effect seen here was because of the maintenance of explicit episodic representations of the primes, which decayed rapidly (e.g., Bock \& Griffin, 2000).

\section{Contextual Embedding Does Not Eliminate Repetition Priming From Spoken Words}

Previous studies found that contextual embedding of primes reduced or even eliminated repetition priming effects (e.g., Coane \& Balota, 2010; Levy \& Kirsner, 1989; MacLeod, 1989; Masson
\& Macleod, 2000; Oliphant, 1983; Speelman et al., 2002). An account of this decrement of priming effects is that the embedding of primes affects the distinctiveness of the memory traces. The earlier studies had not used the combination of spoken primes and pictorial targets used in the present study, but distinctiveness should be of relevance here as well. Therefore, one might expect to see weaker repetition priming effects than in the earlier study by Jongman and Meyer (2017).

Contrary to this prediction, the repetition priming effect in the no lag condition, which was the only lag condition included in both studies, was numerically stronger in the present than in the earlier study (151 and $181 \mathrm{~ms}$ in Experiment 1 and 2 of the present study, $82 \mathrm{~ms}$ in Experiment 1 of Jongman \& Meyer, 2017). We refrain from any interpretation of the difference in the magnitude of the effects as the two studies differed in many respects. However, we can conclude that sentential embedding did not eliminate the repetition priming effect.

The absence of an effect of sentential context in the present study does not necessarily mean that the distinctiveness account is incorrect. Instead it indicates the need for further studies of the circumstances under which contextual embedding reduces the distinctiveness of individual words and their effectiveness as primes. In the current study the prime words were very prominent, always being the only noun of the sentence and the direct object of the verb. By contrast, earlier studies used more varied sentences featuring multiple nouns. In the present experiments the prime words may have "stuck out" more as particularly distinctive, which may have eliminated any contextual embedding effects. This account fits with the finding that, when embedded in text, lowfrequency words yield more priming than high frequency words, and incongruent words, which do not fit in well with the context, yield more priming than congruent words (MacLeod, 1989; see also Coane \& Balota, 2010).

For the present purposes, it is most important to note that heard word primes, presented in isolation or in sentence contexts, led to substantial repetition priming effects for word production. This is consistent with the view that repetition priming can support speech production in conversation, regardless of whether the words produced by a conversational partner occur in isolation or in utterance contexts.

\section{The Effect of Lag on Contextually Embedded Spoken Primes}

In this study, we included two different lag conditions to compare the rate of decay of the priming effect in Experiment 1 and in Experiment 2. The type of contrasts that we used in our analysis does not allow us to clearly establish at which lag the priming effect disappeared. While we do not intend to make any substantial claims about the longevity of the effect, in this paragraph we will discuss our results in light of previous studies that used a similar paradigm and will outline some of the factors that may affect the longevity of the priming effect.

While mean naming latencies in the no lag and short lag condition were numerically smaller than those in the unrelated condition, mean naming latencies in the long lag condition were virtually identical to those in the unrelated condition. Although no formal comparison was carried out, this suggests that at that point the priming effect had probably faded. This pattern may be unex- 
pected, given that some studies have reported priming effects lasting days or years (Cave, 1997; Mitchell, 2006). However, these studies used paradigms that differed substantially from the present one, most importantly perhaps in the use of prime pictures rather than words. The long-lived effect may, therefore, be based primarily on stable memory representations for the pictures rather than their names. Moreover, memory performance may have been improved by consolidation during sleep (Walker \& Stickgold, 2004), which did not occur during the present study.

The effects of within-experiment lags between primes and targets have been assessed in a number of earlier studies. Consistent with the present results, they found decreasing priming effects with increasing lags. Nonetheless, in previous studies, repetition priming effects were observed at lags exceeding our long lags in both time and amount of intervening materials. For instance, Wheeldon and Monsell (1992) observed repetition after delays of 6 to $12 \mathrm{~min}$ (60 to 120 intervening trials); Monsell et al. (1992) observed repetition priming after 8 to $20 \mathrm{~min}$.

There are many differences between the earlier studies and the present one that may account for any differences in the longevity of the repetition priming effect. One difference is the presence or absence of the sentential embedding of the primes. Presentation of the primes in context does not eliminate the priming effect at short lags, but it may affect the rate of decay. This suggestion could be assessed in a study directly contrasting the effects of isolated word primes versus embedded primes at different lags. Another potentially important difference to the earlier studies is that our participants heard the primes, whereas the participants of the earlier studies produced the prime words themselves. Producing words at study leads to better memory performance than hearing or reading them (e.g., Fawcett, Quinlan, \& Taylor, 2012; MacLeod \& Bodner, 2017; MacLeod, Gopie, Hourihan, Neary, \& Ozubko, 2010; Zormpa, Brehm, Hoedemaker, \& Meyer, 2019). This holds for explicit memory tasks (free recall and recognition) and implicit memory tasks (fragment completion and picture naming; but see Kahn \& Arnold, 2015 for equal production-to-production and comprehension-to-production priming). To assess this proposal a study would have to contrast the effects of self-produced versus heard primes at different lags.

On the basis of our findings, it is difficult to estimate how long repetition priming may last in everyday conversations. Turns in conversations vary greatly in length. The average duration of turns in casual conversation has been estimated to be about $2 \mathrm{~s}$ (one or two sentences; Levinson, 2016). We find repetition priming with a lag of $1 \mathrm{~min}$, corresponding to 10 intervening trials. Thus, a conservative estimate of the impact of repetition priming in conversation is that speakers should benefit from it at least during three or four turns following the prime. The impact of the prime may vary given the elapsed time as well as the amount and type of intervening items. Further research teasing apart the impact of these variables would be very valuable not only for a better understanding of the role of repetition priming in conversation, but also for elucidating the mechanisms underlying repetition priming.

\section{Linguistic Dual-Tasking Does Not Affect Repetition Priming}

Finally, we replicated the earlier finding that repetition priming occurs when participants plan words while listening to primes. In fact, the joint analyses of the results of Experiments 1 and 2 showed that the priming effects in the two experiments did not differ significantly in strength. This replicates the findings by Jongman and Meyer (2017) and extends them by demonstrating that heard words also prime picture naming in a linguistic dualtasking setting when the primes are embedded in sentence contexts and when there is a lag between prime and target. Work using different paradigms has also shown that priming occurs under conditions of divided attention, though the priming effect can be weaker than under full attention conditions (for a meta-analysis see Spataro et al., 2011). The finding that the size of the repetition priming effect was largely unaffected by the division of attention is consistent with the suggestion that strategic processing of the primes did not contribute much to the priming effect.

The occurrence of repetition priming during speech planning should be followed up in further research. In the present study primes were processed sufficiently to generate priming effects, but, as their online processing was not tracked, we cannot say whether and how it was affected by the speech planning task. Prime processing might have been delayed or shallower. The study by Jongman and Meyer (2017) included an associative priming condition in addition to the repetition priming condition, and found that in one of the two experiments the associative priming effect was eliminated under linguistic dual-tasking. This suggests that the processing of the primes was affected either because attention had to be divided between comprehension and speech planning, or because of interference between representations accessed for production and comprehension. Furthermore, the distractor pictures were named more slowly in our Experiment 2 than in Experiment 1 , and, correspondingly, in Jongman and Meyer's plan condition than in their no plan conditions. This also indicates that the processing of the spoken input was hindered by concurrent speech planning. Further investigating such interference effects would be important to gain a better understanding of the relationships between the speech comprehension and production system and the way they can be simultaneously engaged in conversation.

While the results of this experiment suggest that repetition priming can occur during linguistic dual-tasking, our experimental set-up differed in many ways from real-life conversational settings. One important difference was that in our experiments, the Picture 2-naming task was not contingent on the content of the spoken prime, whereas in in everyday conversations people typically respond to the content of their partner's utterances. This means that during conversations participants might prioritize comprehension processes more, which could strengthen repetition priming from comprehension to production and, therefore, lead to more alignment between speakers. However, in our study (especially in Experiments 1 and 2), participants may very well have been aware of the fact that many of the prime words were target names, which may have encouraged them to listen carefully to the primes. An important question for further research is how people distribute their attention in conversation, and how this affects mutual priming.

Another important difference to everyday conversations is that in our study participants were required to produce the names of the target pictures using nouns that had or had not occurred before. By contrast, in conversation speakers often choose not to use full noun phrases to refer to concepts introduced before, but instead use pronouns (Arnold, 2010; Arnold \& Zerkle, 2019). In fact, com- 
prehension studies have shown a repeated name penalty, that is, longer reading times for noun phrases in contexts where pronouns were expected (e.g., Kennison \& Gordon, 1997). There is a substantial literature on the linguistic and cognitive variables that affect preferences for nouns or pronouns (e.g., Arnold, Eisenband, Brown-Schmidt, \& Trueswell, 2000; Brown-Schmidt, Byron, \& Tanenhaus, 2005; Fukumura \& Van Gompel, 2012). However, little is known about the cognitive processes occurring when speakers decide whether to use a noun or a pronoun. Our data do not speak to this issue, but only show that, when a noun is to be produced, the speed of producing it can be reduced through repetition priming. An important question for further research is how speakers' choices between nouns and pronouns might be affected by linguistic dual-tasking.

\section{Conclusions}

Mutual repetition priming between interlocutors might support fluent conversation in at least two ways, that is, by contributing to the establishment of common ground and by increasing the speed of speech planning. This pivotal role of priming can only be confirmed if it occurs under the conditions prevailing in conversation. We showed that repetition priming for word production occurred when primes were embedded in sentences, when the target word followed the prime immediately or after a short lag, and regardless of whether or not participants were planning to name a distractor picture while listening to the primes. These results suggest that repetition priming may indeed aid speech planning in conversation by reducing processing costs.

\section{References}

Allum, P. H., \& Wheeldon, L. R. (2007). Planning scope in spoken sentence production: The role of grammatical units. Journal of Experimental Psychology: Learning, Memory, and Cognition, 33, 791-810. http://dx.doi.org/10.1037/0278-7393.33.4.791

Almor, A. (2008). Why does language interfere with vision-based tasks? Experimental Psychology, 55, 260-268. http://dx.doi.org/10.1027/16183169.55.4.260

Arnold, J. E. (2010). How speakers refer: The role of accessibility. Language and Linguistics Compass, 4, 187-203. http://dx.doi.org/10.1111/ j.1749-818X.2010.00193.x

Arnold, J. E. (2016). Explicit and emergent mechanisms of information status. Topics in Cognitive Science, 8, 737-760. http://dx.doi.org/10 $.1111 /$ tops. 12220

Arnold, J. E., Eisenband, J. G., Brown-Schmidt, S., \& Trueswell, J. C. (2000). The rapid use of gender information: Evidence of the time course of pronoun resolution from eyetracking. Cognition, 76, B13-B26. http:// dx.doi.org/10.1016/S0010-0277(00)00073-1

Arnold, J. E., \& Zerkle, S. A. (2019). Why do people produce pronouns? Pragmatic selection vs. rational models. Language, Cognition and Neuroscience, 34, 1152-1175. http://dx.doi.org/10.1080/23273798.2019 .1636103

Bard, E. G., Aylett, M. P., Trueswell, J., \& Tanenhaus, M. (2004). Referential form, word duration, and modeling the listener in spoken dialogue. In J. C. Trueswell \& M. K. Tanenhaus (Eds.), Approaches to studying world-situated language use: Bridging the language-as-product and language-as-action traditions (pp. 173-191). Cambridge, MA: MIT Press.

Barry, C., Hirsh, K. W., Johnston, R. A., \& Williams, C. L. (2001). Age of acquisition, word frequency, and the locus of repetition priming of picture naming. Journal of Memory and Language, 44, 350-375. http:// dx.doi.org/10.1006/jmla.2000.2743
Barry, C., Johnston, R. A., \& Wood, R. F. (2006). Effects of age of acquisition, age, and repetition priming on object naming. Visual Cognition, 13, 911-927. http://dx.doi.org/10.1080/13506280544000101

Barthel, M., Meyer, A. S., \& Levinson, S. C. (2017). Next speakers plan their turn early and speak after turn-final "go-signals". Frontiers in Psychology, 8, 393. http://dx.doi.org/10.3389/fpsyg.2017.00393

Barthel, M., Sauppe, S., Levinson, S. C., \& Meyer, A. S. (2016). The timing of utterance planning in task-oriented dialogue: Evidence from a novel list-completion paradigm. Frontiers in Psychology. Advance online publication. http://dx.doi.org/10.3389/fpsyg.2016.01858

Bates, D., Kliegl, R., Vasishth, S., \& Baayen, H. (2015). Parsimonious mixed models. arXiv preprint arXiv: 1506.04967. Retrieved from https:// arxiv.org/abs/1506.04967

Bates, D., Mächler, M., Bolker, B., \& Walker, S. (2015). Fitting linear mixed-effects models using lme4. Journal of Statistical Software. Advance online publication. http://dx.doi.org/10.18637/jss.v067.i01

Bock, J. K. (1986). Syntactic persistence in language production. Cognitive Psychology, 18, 355-387. http://dx.doi.org/10.1016/0010-0285(86) 90004-6

Bock, K., Dell, G. S., Chang, F., \& Onishi, K. H. (2007). Persistent structural priming from language comprehension to language production. Cognition, 104, 437-458. http://dx.doi.org/10.1016/j.cognition 2006.07.003

Bock, K., \& Griffin, Z. M. (2000). The persistence of structural priming: Transient activation or implicit learning? Journal of Experimental Psychology: General, 129, 177-192. http://dx.doi.org/10.1037/0096-3445 129.2.177

Boersma, P., \& Weenink, D. (2005). Praat: Doing phonetics by computer. 2009. Retrieved from http://www.praat.org

Bögels, S., Casillas, M., \& Levinson, S. C. (2018). Planning versus comprehension in turn-taking: Fast responders show reduced anticipatory processing of the question. Neuropsychologia, 109, 295-310. http:// dx.doi.org/10.1016/j.neuropsychologia.2017.12.028

Bögels, S., Magyari, L., \& Levinson, S. C. (2015). Neural signatures of response planning occur midway through an incoming question in conversation. Scientific Reports, 5, 12881. http://dx.doi.org/10.1038/srep 12881

Boiteau, T. W., Malone, P. S., Peters, S. A., \& Almor, A. (2014). Interference between conversation and a concurrent visuomotor task. Journal of Experimental Psychology: General, 143, 295-311. http://dx.doi.org/ 10.1037/a0031858

Brown, A. S., Neblett, D. R., Jones, T. C., \& Mitchell, D. B. (1991). Transfer of processing in repetition priming: Some inappropriate findings. Journal of Experimental Psychology: Learning, Memory, and Cognition, 17, 514-525. http://dx.doi.org/10.1037/0278-7393.17.3.514

Brown-Schmidt, S. (2012). Beyond common and privileged: Gradient representations of common ground in real-time language use. Language and Cognitive Processes, 27, 62-89. http://dx.doi.org/10.1080/016 90965.2010.543363

Brown-Schmidt, S., Byron, D. K., \& Tanenhaus, M. K. (2005). Beyond salience: Interpretation of personal and demonstrative pronouns. Journal of Memory and Language, 53, 292-313. http://dx.doi.org/10.1016/j.jml .2005.03.003

Brown-Schmidt, S., \& Duff, M. C. (2016). Memory and Common Ground Processes in Language Use. Topics in Cognitive Science, 8, 722-736. http://dx.doi.org/10.1111/tops. 12224

Brysbaert, M., Mandera, P., \& Keuleers, E. (2018). The word frequency effect in word processing: An updated review. Current Directions in Psychological Science, 27, 45-50. http://dx.doi.org/10.1177/096 3721417727521

Cave, C. B. (1997). Very long-lasting priming in picture naming. Psychological Science, 8, 322-325. http://dx.doi.org/10.1111/j.1467-9280.1997 .tb00446.x 
Clark, H. H., \& Marshall, C. (1978). Reference diaries. In D. L. Waltz (Ed.), Theoretical issues in natural language processing (Vol. 2, pp. 57-63). New York, NY: Association for Computing Machinery.

Clark, H. H., \& Marshall, C. R. (1981). Definite knowledge and mutual knowledge. In A. K. Joshi, B. L. Webber, \& I. A. Sag (Eds.), Elements of discourse understanding (pp. 10-63). Cambridge, UK: Cambridge University Press.

Cleland, A. A., \& Pickering, M. J. (2003). The use of lexical and syntactic information in language production: Evidence from the priming of noun-phrase structure. Journal of Memory and Language, 49, 214-230. http://dx.doi.org/10.1016/S0749-596X(03)00060-3

Coane, J. H., \& Balota, D. A. (2010). Repetition priming across distinct contexts: Effects of lexical status, word frequency, and retrieval test. Quarterly Journal of Experimental Psychology, 63, 2376-2398. http:// dx.doi.org/10.1080/17470211003687546

Corps, R. E., Crossley, A., Gambi, C., \& Pickering, M. J. (2018). Early preparation during turn-taking: Listeners use content predictions to determine what to say but not when to say it. Cognition, 175, 77-95. http://dx.doi.org/10.1016/j.cognition.2018.01.015

Costa, A., Miozzo, M., \& Caramazza, A. (1999). Lexical Selection in Bilinguals: Do Words in the Bilingual's Two Lexicons Compete for Selection? Journal of Memory and Language, 41, 365-397. http://dx.doi .org/10.1006/jmla.1999.2651

Dell, G. S., \& Ferreira, V. S. (2016). Thirty years of structural priming: An introduction to the special issue. Journal of Memory and Language, 91, 1-4. http://dx.doi.org/10.1016/j.jml.2016.05.005

Duff, M. C., Hengst, J., Tranel, D., \& Cohen, N. J. (2006). Development of shared information in communication despite hippocampal amnesia. Nature Neuroscience, 9, 140-146. http://dx.doi.org/10.1038/nn1601

Duñabeitia, J. A., Crepaldi, D., Meyer, A. S., New, B., Pliatsikas, C., Smolka, E., \& Brysbaert, M. (2017). MultiPic: A standardized set of 750 drawings with norms for six European languages. Quarterly Journal of Experimental Psychology, 71, 808-816.

Durso, F. T., \& Johnson, M. K. (1979). Facilitation in naming and categorizing repeated pictures and words. Journal of Experimental Psychology: Human Learning and Memory, 5, 449-459. http://dx.doi.org/10 $.1037 / 0278-7393.5 .5 .449$

Fairs, A., Bögels, S., \& Meyer, A. S. (2018). Dual-tasking with simple linguistic tasks: Evidence for serial processing. Acta Psychologica, 191, 131-148. http://dx.doi.org/10.1016/j.actpsy.2018.09.006

Fargier, R., \& Laganaro, M. (2016). Neurophysiological modulations of non-verbal and verbal dual-tasks interference during word planning. PLoS ONE, 11, e0168358. http://dx.doi.org/10.1371/journal.pone .0168358

Fargier, R., \& Laganaro, M. (2019). Interference in speaking while hearing and vice versa. Scientific Reports, 9, 5375. http://dx.doi.org/10.1038/ s41598-019-41752-7

Fawcett, J. M., Quinlan, C. K., \& Taylor, T. L. (2012). Interplay of the production and picture superiority effects: A signal detection analysis. Memory, 20, 655-666. http://dx.doi.org/10.1080/09658211.2012 .693510

Forster, K. I., \& Davis, C. (1984). Repetition priming and frequency attenuation in lexical access. Journal of Experimental Psychology: Learning, Memory, and Cognition, 10, 680-698. http://dx.doi.org/10 $.1037 / 0278-7393.10 .4 .680$

Francis, W. S. (2014). Repetition priming in picture naming: Sustained learning through the speeding of multiple processes. Psychonomic Bulletin \& Review, 21, 1301-1308. http://dx.doi.org/10.3758/s13423-0140610-9

Francis, W. S., Camacho, A., \& Lara, C. (2014). Words translated in sentence contexts produce repetition priming in visual word comprehension and spoken word production. Memory \& Cognition, 42, 1143-1154. http://dx.doi.org/10.3758/s13421-014-0423-0
Francis, W. S., Corral, N. I., Jones, M. L., \& Sáenz, S. P. (2008). Decomposition of repetition priming components in picture naming. Journal of Experimental Psychology: General, 137, 566-590. http://dx .doi.org/10.1037/0096-3445.137.3.566

Fukumura, K., \& van Gompel, R. P. (2012). Producing pronouns and definite noun phrases: Do speakers use the addressee's discourse model? Cognitive Science, 36, 1289-1311. http://dx.doi.org/10.1111/j.15516709.2012.01255.x

Gabrieli, J. D., Vaidya, C. J., Stone, M., Francis, W. S., Thompson-Schill, S. L., Fleischman, D. A., . . Wilson, R. S. (1999). Convergent behavioral and neuropsychological evidence for a distinction between identification and production forms of repetition priming. Journal of Experimental Psychology: General, 128, 479-498. http://dx.doi.org/10.1037/ 0096-3445.128.4.479

Garrod, S., \& Pickering, M. J. (2009). Joint action, interactive alignment, and dialog. Topics in Cognitive Science, 1, 292-304. http://dx.doi.org/ 10.1111/j.1756-8765.2009.01020.x

Glaser, W. R., \& Düngelhoff, F.-J. (1984). The time course of picture-word interference. Journal of Experimental Psychology: Human Perception and Performance, 10, 640-654. http://dx.doi.org/10.1037/0096-1523.10 .5 .640

Hartsuiker, R. J., Bernolet, S., Schoonbaert, S., Speybroeck, S., \& Vanderelst, D. (2008). Syntactic priming persists while the lexical boost decays: Evidence from written and spoken dialogue. Journal of Memory and Language, 58, 214-238. http://dx.doi.org/10.1016/j.jml.2007.07 .003

Heath, S., McMahon, K., Nickels, L., Angwin, A., MacDonald, A., van Hees, S., . . . Copland, D. (2012). Priming picture naming with a semantic task: An fMRI investigation. PLoS ONE, 7, e32809. http://dx .doi.org/10.1371/journal.pone.0032809

Horton, W. S. (2007). The influence of partner-specific memory associations on language production: Evidence from picture naming. Language and Cognitive Processes, 22, 1114-1139. http://dx.doi.org/10.1080/ 01690960701402933

Horton, W. S., \& Gerrig, R. J. (2005). Conversational common ground and memory processes in language production. Discourse Processes, 40, 1-35. http://dx.doi.org/10.1207/s15326950dp4001_1

Horton, W. S., \& Gerrig, R. J. (2016). Revisiting the memory-based processing approach to common ground. Topics in Cognitive Science, 8, $780-795$.

Hughes, J. W., \& Schnur, T. T. (2017). Facilitation and interference in naming: A consequence of the same learning process? Cognition, 165, 61-72. http://dx.doi.org/10.1016/j.cognition.2017.04.012

Indefrey, P., \& Levelt, W. J. (2004). The spatial and temporal signatures of word production components. Cognition, 92, 101-144. http://dx.doi.org/ 10.1016/j.cognition.2002.06.001

Jacobs, C. L., Yiu, L. K., Watson, D. G., \& Dell, G. S. (2015). Why are repeated words produced with reduced durations? Evidence from inner speech and homophone production. Journal of Memory and Language, 84, 37-48. http://dx.doi.org/10.1016/j.jml.2015.05.004

Jacoby, L. L., \& Dallas, M. (1981). On the relationship between autobiographical memory and perceptual learning. Journal of Experimental Psychology: General, 110, 306-340. http://dx.doi.org/10.1037/00963445.110.3.306

Johnson, C. J., Paivio, A., \& Clark, J. M. (1996). Cognitive components of picture naming. Psychological Bulletin, 120, 113-139. http://dx.doi.org/ 10.1037/0033-2909.120.1.113

Jongman, S. R., \& Meyer, A. S. (2017). To plan or not to plan: Does planning for production remove facilitation from associative priming? Acta Psychologica, 181, 40-50. http://dx.doi.org/10.1016/j.actpsy.2017 .10 .003

Kahn, J. M., \& Arnold, J. E. (2015). Articulatory and lexical repetition effects on durational reduction: Speaker experience vs. common ground. 
Language, Cognition and Neuroscience, 30, 103-119. http://dx.doi.org/ 10.1080/01690965.2013.848989

Keane, M. M., Cruz, M. E., \& Verfaellie, M. (2015). Attention and implicit memory: Priming-induced benefits and costs have distinct attentional requirements. Memory \& Cognition, 43, 216-225. http://dx.doi.org/10 .3758/s13421-014-0464-4

Kennison, S. M., \& Gordon, P. C. (1997). Comprehending referential expressions during reading: Evidence from eye tracking. Discourse Processes, 24, 229-252. http://dx.doi.org/10.1080/01638539709545014

Keuleers, E., Brysbaert, M., \& New, B. (2010). SUBTLEX-NL: A new measure for Dutch word frequency based on film subtitles. Behavior Research Methods, 42, 643-650. http://dx.doi.org/10.3758/BRM.42.3 .643

Levinson, S. C. (2016). Turn-taking in human communication-Origins and implications for language processing. Trends in Cognitive Sciences, 20, 6-14. http://dx.doi.org/10.1016/j.tics.2015.10.010

Levinson, S. C., \& Torreira, F. (2015). Timing in turn-taking and its implications for processing models of language. Frontiers in Psychology, 6, 731. http://dx.doi.org/10.3389/fpsyg.2015.00731

Levy, B. A., \& Kirsner, K. (1989). Reprocessing text: Indirect measures of word and message level processes. Journal of Experimental Psychology: Learning, Memory, and Cognition, 15, 407-417. http://dx.doi.org/10 $.1037 / 0278-7393.15 .3 .407$

Lindsay, L., Gambi, C., \& Rabagliati, H. (2019). Preschoolers optimize the timing of their conversational turns through flexible coordination of language comprehension and production. Psychological Science, 30, 504-515. http://dx.doi.org/10.1177/0956797618822802

MacDonald, P. A., \& MacLeod, C. M. (1998). The influence of attention at encoding on direct and indirect remembering. Acta Psychologica, 98, 291-310. http://dx.doi.org/10.1016/S0001-6918(97)00047-4

MacLeod, C. M. (1989). Word context during initial exposure influences degree of priming in word fragment completion. Journal of Experimental Psychology: Learning, Memory, and Cognition, 15, 398-406. http:// dx.doi.org/10.1037/0278-7393.15.3.398

MacLeod, C. M., \& Bodner, G. E. (2017). The production effect in memory. Current Directions in Psychological Science, 26, 390-395. http://dx.doi.org/10.1177/0963721417691356

MacLeod, C. M., Gopie, N., Hourihan, K. L., Neary, K. R., \& Ozubko, J. D. (2010). The production effect: Delineation of a phenomenon. Journal of Experimental Psychology: Learning, Memory, and Cognition, 36, 671-685. http://dx.doi.org/10.1037/a0018785

Magyari, L., De Ruiter, J. P., \& Levinson, S. C. (2017). Temporal preparation for speaking in question-answer sequences. Frontiers in Psychology, 8, 211. http://dx.doi.org/10.3389/fpsyg.2017.00211

Masson, M. E. J., \& MacLeod, C. M. (2000). Taking the "text" out of context effects in repetition priming of word identification. Memory \& Cognition, 28, 1090-1097. http://dx.doi.org/10.3758/BF03211810

McKone, E. (1995). Short-term implicit memory for words and nonwords. Journal of Experimental Psychology: Learning, Memory, and Cognition, 21, 1108-1126. http://dx.doi.org/10.1037/0278-7393.21.5.1108

McKone, E. (1998). The decay of short-term implicit memory: Unpacking lag. Memory \& Cognition, 26, 1173-1186. http://dx.doi.org/10.3758/ BF03201193

McKone, E., \& Dennis, C. (2000). Short-term implicit memory: Visual, auditory, and cross-modality priming. Psychonomic Bulletin \& Review, 7, 341-346. http://dx.doi.org/10.3758/BF03212991

McQueen, J. M., \& Meyer, A. S. (2018). Towards a comprehensive cognitive architecture for language use. In P. Hagoort (Ed.), Human language: From genes and brain to behavior (pp. 85-96). Cambridge, MA: MIT Press.

Mitchell, D. B. (2006). Nonconscious priming after 17 years: Invulnerable implicit memory? Psychological Science, 17, 925-929. http://dx.doi.org/ 10.1111/j.1467-9280.2006.01805.x
Mitchell, D. B., \& Brown, A. S. (1988). Persistent repetition priming in picture naming and its dissociation from recognition memory. Journal of Experimental Psychology: Learning, Memory, and Cognition, 14, 213 222. http://dx.doi.org/10.1037/0278-7393.14.2.213

Monsell, S., Matthews, G. H., \& Miller, D. C. (1992). Repetition of lexicalization across languages: A further test of the locus of priming. Quarterly Journal of Experimental Psychology, 44, 763-783. http://dx .doi.org/10.1080/14640749208401308

Mulligan, N. W. (1997). Attention and implicit memory tests: The effects of varying attentional load on conceptual priming. Memory \& Cognition, 25, 11-17. http://dx.doi.org/10.3758/BF03197281

Mulligan, N. W. (1998). The role of attention during encoding in implicit and explicit memory. Journal of Experimental Psychology: Learning, Memory, and Cognition, 24, 27-47. http://dx.doi.org/10.1037/02787393.24.1.27

Mulligan, N. W., \& Stone, M. (1999). Attention and conceptual priming: Limits on the effects of divided attention in the category-exemplar production task. Journal of Memory and Language, 41, 253-280. http:// dx.doi.org/10.1006/jmla.1999.2648

Oliphant, G. W. (1983). Repetition and recency effects in word recognition. Australian Journal of Psychology, 35, 393-403. http://dx.doi.org/ 10.1080/00049538308258751

Oppenheim, G. M., Dell, G. S., \& Schwartz, M. F. (2010). The dark side of incremental learning: A model of cumulative semantic interference during lexical access in speech production. Cognition, 114, 227-252. http://dx.doi.org/10.1016/j.cognition.2009.09.007

Ostergaard, A. L. (1998). The effects on priming of word frequency, number of repetitions, and delay depend on the magnitude of priming. Memory \& Cognition, 26, 40-60. http://dx.doi.org/10.3758/ BF03211369

Pickering, M. J., \& Garrod, S. (2004). Toward a mechanistic psychology of dialogue. Behavioral and Brain Sciences, 27, 169-190. http://dx.doi .org/10.1017/S0140525X04000056

Pickering, M. J., \& Garrod, S. (2013). An integrated theory of language production and comprehension. Behavioral and Brain Sciences, 36 , 329-347. http://dx.doi.org/10.1017/S0140525X12001495

Powell, M. J. (2009). The BOBYQA algorithm for bound constrained optimization without derivatives (Report NA2009/06). Cambridge, UK University of Cambridge.

Schriefers, H., Meyer, A. S., \& Levelt, W. J. (1990). Exploring the time course of lexical access in language production: Picture-word interference studies. Journal of Memory and Language, 29, 86-102. http://dx .doi.org/10.1016/0749-596X(90)90011-N

Segaert, K., Kempen, G., Petersson, K. M., \& Hagoort, P. (2013). Syntactic priming and the lexical boost effect during sentence production and sentence comprehension: An fMRI study. Brain and Language, 124, 174-183. http://dx.doi.org/10.1016/j.bandl.2012.12.003

Segaert, K., Wheeldon, L., \& Hagoort, P. (2016). Unifying structural priming effects on syntactic choices and timing of sentence generation Journal of Memory and Language, 91, 59-80. http://dx.doi.org/10 .1016/j.jml.2016.03.011

Sjerps, M. J., \& Meyer, A. S. (2015). Variation in dual-task performance reveals late initiation of speech planning in turn-taking. Cognition, 136, 304-324. http://dx.doi.org/10.1016/j.cognition.2014.10.008

Smith, M., \& Wheeldon, L. (1999). High level processing scope in spoken sentence production. Cognition, 73, 205-246. http://dx.doi.org/10.1016/ S0010-0277(99)00053-0

Spataro, P., Cestari, V., \& Rossi-Arnaud, C. (2011). The relationship between divided attention and implicit memory: A meta-analysis. Acta Psychologica, 136, 329-339. http://dx.doi.org/10.1016/j.actpsy.2010.12 .007

Speelman, C. P., Simpson, T. A., \& Kirsner, K. (2002). The unbearable lightness of priming. Acta Psychologica, 111, 191-204. http://dx.doi .org/10.1016/S0001-6918(02)00049-5 
Team, A. (2012). Audacity and recorder (Version, 2(0)). Retrieved from https://www.audacityteam.org/

Team, R. C. (2017). R: A language and environment for statistical computing. Vienna, Austria: R Foundation for Statistical Computing. Retrieved from https://www.R-project.org

van Turennout, M., Bielamowicz, L., \& Martin, A. (2003). Modulation of neural activity during object naming: Effects of time and practice. Cerebral Cortex, 13, 381-391. http://dx.doi.org/10.1093/cercor/13.4 .381

Versace, R., \& Nevers, B. (2003). Word frequency effect on repetition priming as a function of prime duration and delay between the prime and the target. British Journal of Psychology, 94, 389-408. http://dx.doi.org/ 10.1348/000712603767876299

Walker, M. P., \& Stickgold, R. (2004). Sleep-dependent learning and memory consolidation. Neuron, 44, 121-133. http://dx.doi.org/10.1016/ j.neuron.2004.08.031
Wheeldon, L. R., \& Monsell, S. (1992). The locus of repetition priming of spoken word production. Quarterly Journal of Experimental Psychology, 44, 723-761. http://dx.doi.org/10.1080/14640749208401307

Wolters, G., \& Prinsen, A. (1997). Full versus divided attention and implicit memory performance. Memory \& Cognition, 25, 764-771. http://dx.doi.org/10.3758/BF03211319

Zormpa, E., Brehm, L. E., Hoedemaker, R. S., \& Meyer, A. S. (2019). The production effect and the generation effect improve memory in picture naming. Memory, 27, 340-352. http://dx.doi.org/10.1080/09658211 .2018 .1510966

\section{를 AMERICAN PSYCHOLOGICAL ASSOCIATION APA Journals}

\section{ORDER INFORMATION \\ Subscribe to This Journal for 2021}

Order Online:

Visit at.apa.org/xIm-2021

for pricing and access information.

Call 800-374-2721 or 202-336-5600

Fax 202-336-5568 | TDD/TTY 202-336-6123

Subscription orders must be prepaid. Subscriptions are on a calendar year basis. Please allow 4-6 weeks for delivery of the first issue.

All APA journal subscriptions include Online First journal articles and access to archives. Individuals can receive online access to all of APA's scholarly journals through a subscription to APA PsycNet or through an institutional subscription to the APA PsycArticles ${ }^{\circ}$ database.

Visit AT.APA.ORG/CIRC2021

to browse APA's full journal collection 